\title{
Intradural lumbar disc herniation: illustrative case
}

\author{
Rivka Chinyere Ihejirika, MD, Yixuan Tong, MD, Karan Patel, MD, and Themistocles Protopsaltis, MD
}

Department of Orthopedics, NYU Langone Orthopedic Hospital, New York, New York

BACKGROUND Accounting for less than $0.4 \%$ of disc herniations, intradural lumbar disc herniations (ILDHs) are a rare occurrence primarily described as a complication after lumbar spine surgery. It is speculated that the herniation may propagate intradurally from either an unrecognized dural defect after initial surgery or as a result of adhesions between the dura and posterior longitudinal ligament. This report explores the etiology, presentation, diagnostic evaluation, and treatment of ILDH along with a case report and microsurgery video.

OBSERVATIONS A 67-year-old patient who 1 year earlier had undergone an L2-5 laminectomy and L2-3 decompression with no known complications presented with low back pain and radiating right leg, buttock, and groin pain for 1 month. Physical examination indicated no numbness or weakness. Magnetic resonance imaging demonstrated a large ILDH. A transforaminal interbody fusion was performed followed by a durotomy, ILDH removal, and dural closure. A ventral dural defect was found and repaired during the procedure.

LESSONS The treatment for ILDH is laminectomy with dorsal durotomy. Because ILDH has rarely been described in literature, understanding its presentation is crucial for prompt identification and management.

https://thejns.org/doi/abs/10.3171/CASE21336

KEYWORDS intradural lumbar disc herniation; ILDH; cauda equina syndrome; spine surgery

The first reported case of intradural lumbar disc herniation (ILDH) was documented by Walter E. Dandy in 1942. Dandy, considered to be a pioneer in neurosurgery, described his index patient as a middle-aged laborer who experienced progressive symptoms of incomplete voiding, right leg weakness and numbness, and lumbar radiculopathy for 1 year prior to presentation. ${ }^{1}$ With the aid of roentgenogram and an intrathecal injection of iodized oil, Dandy diagnosed lumbar disc herniation at L4. During surgery, Dandy noted intact cartilage fragments within the dura surrounding the cauda equina (Fig. 1). Since Dandy's initial report, more than 140 cases of ILDH have been reported in the literature. ${ }^{2-6}$

Intradural disc herniations are most common in the lumbar spine $(90 \%)$, followed by the thoracic $(5 \%)$ and cervical spine $(3 \%-5 \%)$. ILDH is estimated to constitute $0.3 \%$ of all disc herniations and occurs most commonly among middle-aged adults. Ninety percent of reported cases of ILDH occur in the lumbar spine at the L4-5 disc space (55\%), followed by L3-4 (16\%) and L5-S1 (10\%) (Table 1). ${ }^{7-9}$

Here, we describe a case of ILDH that occurred in the lumbar spine in the setting of prior lumbar spine surgery and presented with associated cauda equina syndrome. Because existing reports on ILDH in the literature are limited, the purpose of this report is to contribute to the growing knowledge on the incidence, presentation, diagnosis, and management of ILDH and associated conditions.

\section{Illustrative Case \\ Clinical Presentation}

A 67-year-old patient presented 1 year after L2-5 laminectomy and $\mathrm{L} 2-3$ decompression with low back pain and radiating right leg, buttock and groin pain for 1 month. His physical examination was without numbness or weakness. Magnetic resonance imaging (MRI) was performed. Within 1 week, the patient's symptoms progressed with radiating pain into the posterior thighs and groin, numbness and burning in the lower back and perineal region, and difficulty voiding. On repeat examination, he had full strength and normal rectal tone but diminished sensation in his testicles. Straight leg raise testing elicited low back pain.

ABBREVIATIONS CSF = cerebrospinal fluid; ILDH = intradural lumbar disc herniation; LDH = lumbar disc herniation; MRI = magnetic resonance imaging; $\mathrm{PLL}=$ posterior longitudinal ligament.

INCLUDE WHEN CITING Published November 1, 2021; DOI: 10.3171/CASE21336.

SUBMITTED July 26, 2021. ACCEPTED September 16, 2021.

(c) 2021 The authors, CC BY-NC-ND 4.0 (http://creativecommons.org/licenses/by-nc-nd/4.0/). 


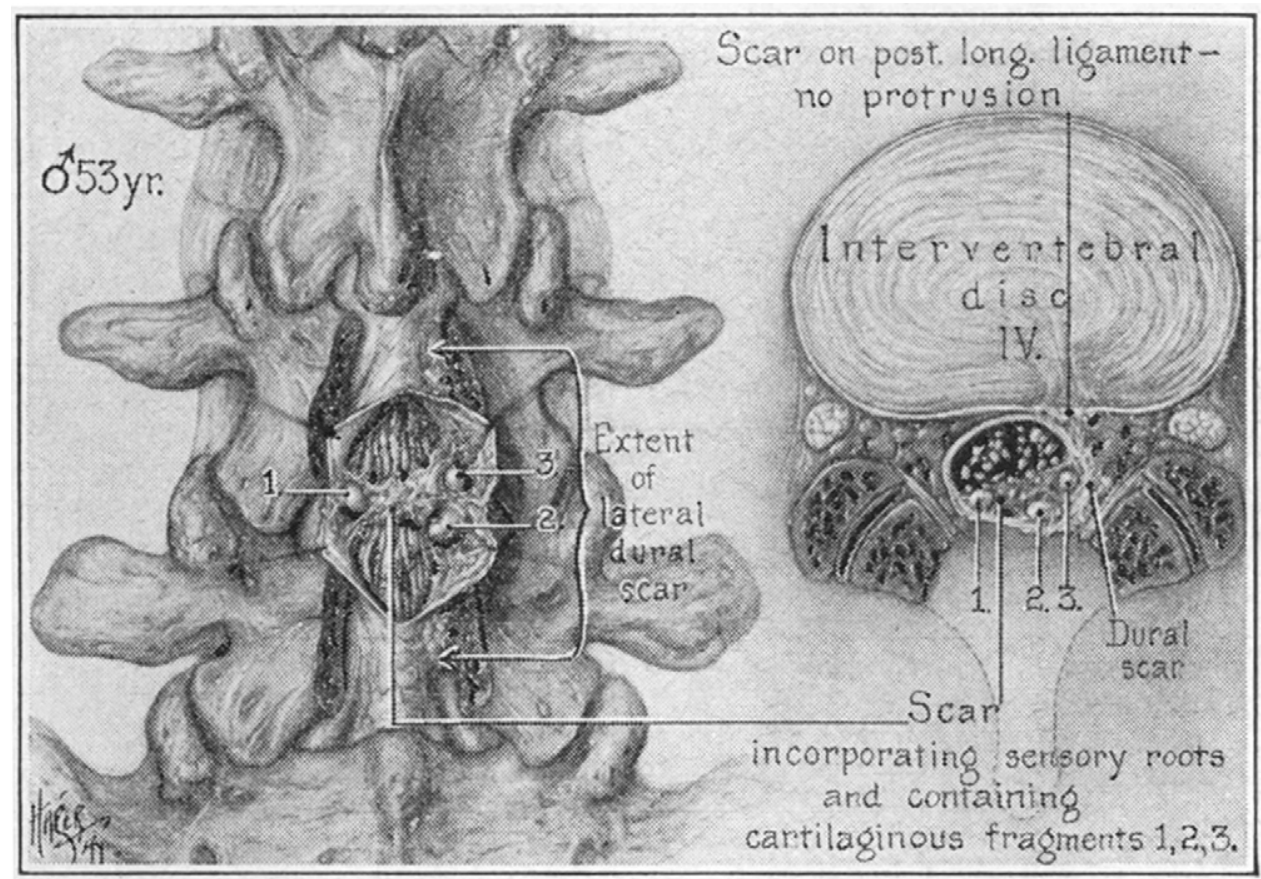

FIG. 1. Operative sketch of intradural lumbar disc herniation drawn by Dandy in 1942. Reproduced with permission from JAMA. Serious complications of ruptured intervertebral disks. JAMA 1942;119(6):474.

\section{Preoperative Imaging}

Standard lumbar spine radiographs demonstrated multilevel spondylotic changes with dynamic instability at L2-3. Specifically, lateral flexion/extension radiographs demonstrated straightening of the lumbar lordosis with retrolisthesis of $L 2$ on $L 3$, which partially reduced on extension compared to flexion. Disc space narrowing was most significant from L2-3 along with widening of the facet joints at the same level. Furthermore, posterior decompression from the patient's prior surgery, extending from L2-5, was visible. T2-weighted MRI of the lumbar spine showed large and small soft tissue masses in the spinal canal at L2-3 with widening of cerebrospinal fluid (CSF) about the superior and inferior borders of the larger mass. Severe compression of the spinal cord rootlets and CSF effacement were present at the same level. Postcontrast MRI depicted rim enhancement about the dominant soft tissue mass (Fig. 2). These findings are highly suggestive of an intradural component of both the dominant and smaller nodules, and combined with the clinical presentation, they necessitate surgical intervention.

\section{Surgical Procedure}

A posterior midline approach was used to perform an L2-3 transforaminal lumbar interbody fusion. The procedure was completed because

\section{TABLE 1. Distribution of ILDH lesions}

\begin{tabular}{lc}
\hline Spinal Level & Distribution \\
\hline L1-2, L2-3 & $<15 \%$ \\
\hline L3-4 & $15-20 \%$ \\
\hline L4-5 & $50-55 \%$ \\
\hline L5-S1 & $10 \%$ \\
\hline
\end{tabular}

of instability using a 9-mm lordotic curved cage and pedicle screws placed at L2-3. The operative microscope was then brought into the field, and the dural opening, intradural work, and dural closure were performed with microsurgical techniques. A midline durotomy was created with a No.15 blade. The arachnoid was progressively opened, and the dura was tacked up to the soft tissue to maintain exposure. Multiple fragments of disc herniation were identified within the cauda equina (Fig. 3). The disc fragments were separated carefully from the nerve roots and extracted (Fig. 3; Video 1). At the completion of this procedure, a defect on the right ventrolateral dural wall with intramural disc fragments was identified. After thorough removal of all disc fragments, the ventrolateral defect was closed with 4-0 Nurolon sutures. The dorsal midline durotomy was then closed with running 4-0 Nurolon sutures and a hydrogel sealant.

VIDEO 1. Clip showing intradural lumbar disc herniation in history and literature followed by clinical presentation and live microsurgery. Click here to view.

\section{Case Outcome}

The patient was kept in a flat position for 3 days, followed by $10^{\circ}$ of elevation every 3 hours as tolerated. A deep bile bag drain and superficial Jackson-Pratt drain were removed sequentially after the patient began ambulating. The patient was started on Lovenox on postoperative day 4.

The patient's testicular sensation improved significantly by postoperative day 4 , and he had a return of spontaneous voiding. By postoperative week 4 , the patient reported improved posterior leg pain, and his perianal numbness had completely resolved. He denied any issues with bowel or bladder control, ambulated without difficulty, and no longer took pain medication. 

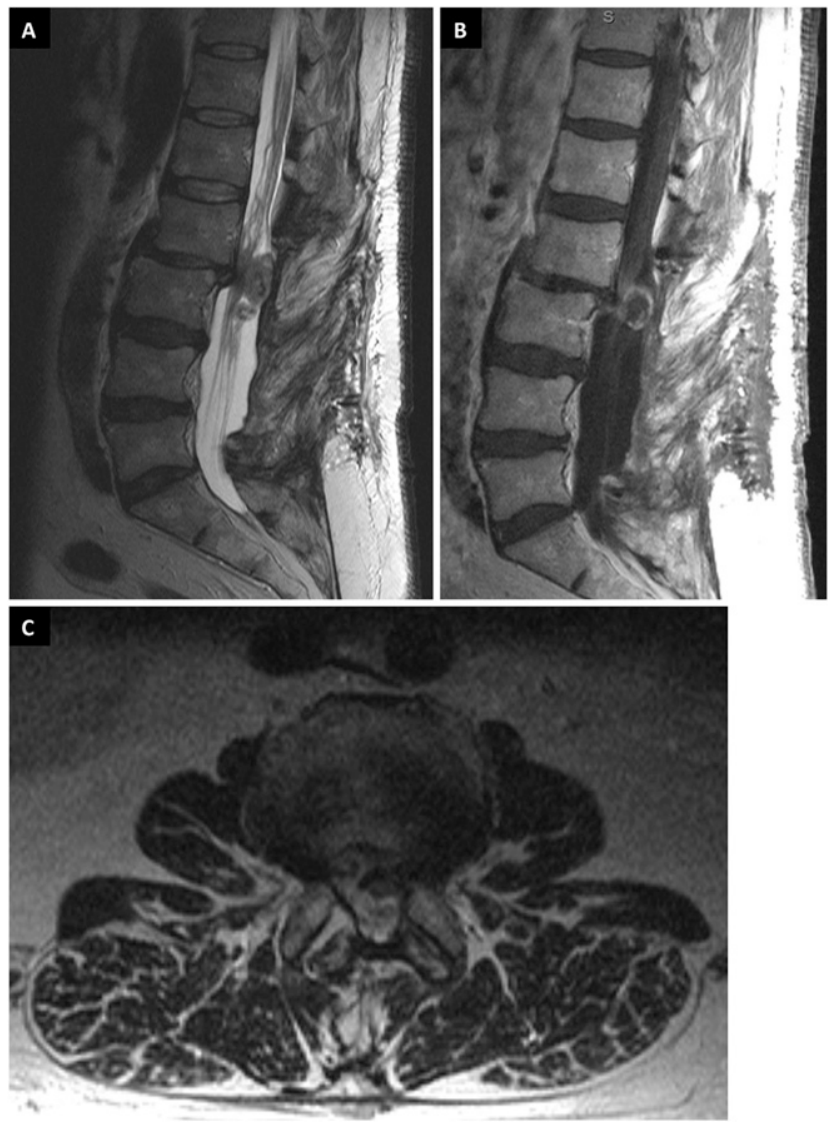

FIG. 2. Lumbar MRI. A: Sagittal T2-weighted MRI of the lumbar spine showing large and small soft tissue masses in the spinal canal at L2-3 with widening of the CSF about the superior and inferior border of the larger mass. The cauda equina is also tethered to the distal mass. B: Postcontrast image shows areas of rim and septation enhancement about the dominant superior soft tissue mass. C: Axial T2-weighted MRI shows severe L2-3 compression of the spinal cord rootlets and CSF effacement.

\section{Discussion}

\section{Pathogenesis}

ILDHs have been found in patients with no prior spinal disease history, patients with recurrent disc herniation, and patients with trauma. As such, several mechanisms have been postulated as to how a herniated disc is able to penetrate dura mater. Regarding patients with no prior spine surgery or trauma, a preexisting abnormality may predispose to dural lesion formation. In an autopsy series, Yildizhan and colleagues discovered dense, inseparable connections between the ventral dura and posterior longitudinal ligament (PLL) in numerous adult and fetal specimens. ${ }^{2}$ In other specimens, the ventral dura was thin in the L4-5 region. These areas of dense attachment and/or thin ventral dura were present in a higher number of adult versus fetal specimens. These findings suggest that congenital abnormalities can predispose to intradural lesion formation but also that these adhesions may occur over time from chronic local inflammation or other factors. In cases of such an adhesion, disc herniation fragments have only one tissue layer to pass through to enter the dura. Finally, traumatic irritation, such as from prior surgeries, unrecognized iatrogenic injury, or trauma,
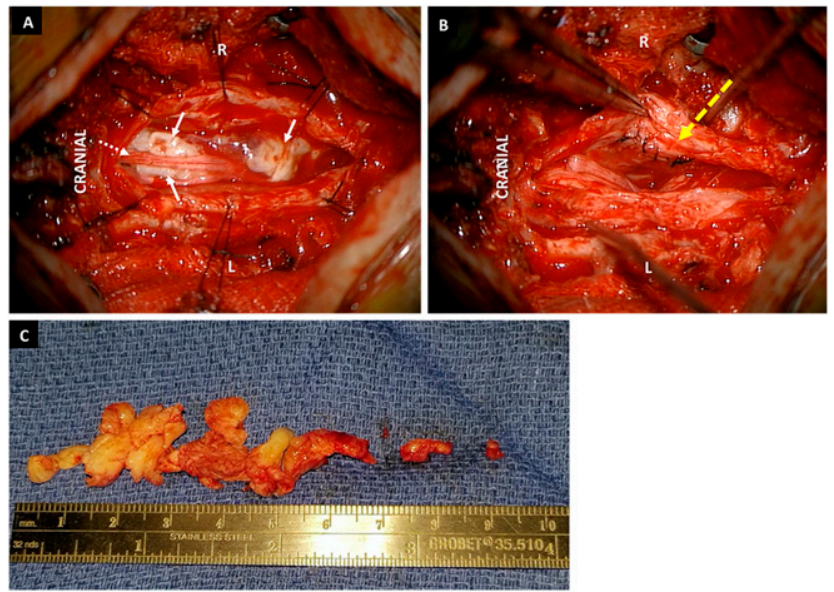

FIG. 3. Operative images. A: Intraoperative view after durotomy showing disc fragments (solid white arrows) wrapped in the nerve rootlets (dashed white arrow). B: View after all disc fragments have been removed and the repaired defect in the right lateral dural wall (dashed yellow arrow). C: Gross pathologic specimen of herniated disc after removal.

may also cause adhesion formation or an opening between the ventral dura mater and PLL. ${ }^{2,10-13}$

\section{Observations}

Diagnosis and Imaging

Distinguishing between lumbar disc herniation (LDH) and ILDH can be challenging because their presentations are similar. ILDH is most often accompanied by a triad of low back pain, radiculopathy, and paresis. Although classic radiculopathy associated with LDH is present, cauda equina syndrome occurs more frequently in the presence of ILDH. Cauda equina syndrome occurs in approximately $0.5 \%$ to $1 \%$ of cases of LDH in general but occurs in $30 \%$ to $60 \%$ of patients with ILDH. Because ILDH is rare, a broad differential diagnosis must be made any time a patient presents with these symptoms, including recurrent $\mathrm{LDH}$, metastatic disease, infection or abscess, cystic growth, and intradural extramedullary tumor. The differential diagnosis for the more common LDH must include ILDH, especially in the presence of cauda equina, bladder dysfunction, prior spinal surgery, or trauma. ${ }^{14-16}$

Expert interpretation of advanced imaging is of paramount importance when differentiating between ILDH and other spinal pathologies. The gold standard for diagnosis is contrast-enhanced MRI. As with $L D H$, the ILDH disc tissue appears hypointense on T1- and T2-weighted imaging. The PLL can be visualized as thinning out and being replaced by disc tissue. In cases of gradual herniation, intravenous contrast permeates the neovasculature of granulation tissue surrounding the intradural fragment and it appears as a rimenhancing lesion. ${ }^{15,17}$ Choi et al. ${ }^{16}$ coined the hawk-beak sign as a finding on axial MRI sequencing, in which hard cartilaginous tissue abuts the ventral portion of the herniated disc fragment, creating a sharp beak-like angle. As the disc fragment migrates through the dura, it may be caught and appear as a Y-sign in the dural wall. This intramural location has been termed an intradural extraarachnoid lumbar disc herniation. ${ }^{8,18}$ Others argue that high-resolution three-dimensional constructive interference steady-state MRI should be used to supplement standard MRI. This sequence can be used 

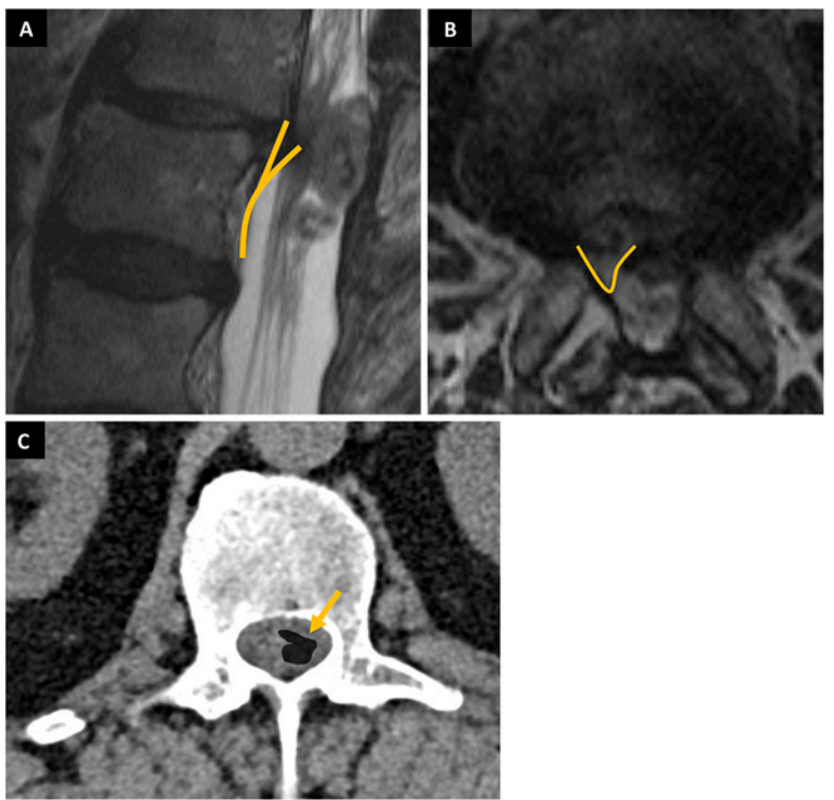

FIG. 4. Radiographic signs of ILDH. A: The Y-sign on MRI (yellow lines). B: The hawk beak sign on MRI (yellow line). C: Intradural gas on computed tomography (yellow arrow).

in patients who are not able to receive contrast, and it helps to identify tissue planes, preferentially outlining the location of a disc herniation within a defect. ${ }^{19}$ Computed tomography imaging may show gas in the epidural space (Fig. 4). ${ }^{20,21}$ Acute disc herniations may not produce these radiographic findings. Furthermore, there are numerous case reports of herniated fragments that become sequestered in the dural sac and migrate cranially. ${ }^{22,23}$

A classification system proposed by Mut et al. breaks down ILDH into two types based on the anatomical location of the herniation. ${ }^{24}$ Type $A$ is described as occurring in the main column of the dural sac whereas type B herniations are at the lateral exit of the nerve root. Over time, this classification has had limited diagnostic or prognostic utility, and for simplicity, other authors refer to a herniation into the preganglionic area of the nerve root as an intraradicular herniation. ${ }^{24}$

\section{Prognosis}

Even in the presence of intense scrutiny and advanced imaging, most ILDHs are found intraoperatively. The incidence of ILDH may be underestimated because of low preoperative suspicion and insufficient intraoperative evaluation. Ducati et al. described an incidence of $1.76 \%$ in their clinical practice. ${ }^{15}$ As standard of care, in cases in which the amount of disc retrieved during a discectomy is less than anticipated based on preoperative imaging, some surgeons routinely examine the ventral surface of the dura or preform a durotomy to search for possible fragments.

The prognosis for recovery in the face of cauda equina syndrome is favorable with prompt surgical intervention. Most authors report complete or near complete recovery of sensation and function.

\section{Lessons}

The authors' preferred treatment for ILDH is a laminectomy with dorsal durotomy. The procedure can involve either open or minimally invasive surgery, with or without a transforaminal lumbar interbody fusion (depending on spinal segment instability) and with or without repair of ventral dural defect if found. Because an ILDH must pass through the ventral surface of the dura, a ventral defect may be found intraoperatively. These defects are often irreparable but can be managed with a fibrin-thrombin patch. ${ }^{12,25}$ Per Ducati et al., a watertight closure of the anterior dural sheath is not essential because doing so can pose a risk to nearby nerve rootlets. ${ }^{15}$ They reported on five cases of ILDH and only sutured the anterior defect in one patient. All patients in the series showed improvement or complete resolution of their symptoms after herniation removal regardless of anterior defect closure. ${ }^{15}$ Because the evidence on ILDH remains limited, further studies are warranted to investigate the management of such pathology.

\section{References}

1. Dandy WE. Serious complications of ruptured intervertebral disks. JAMA. 1942;119(6):474.

2. Yildizhan A, Paşaoğlu A, Okten T, Ekinci N, Aycan K, Aral O. Intradural disc herniations pathogenesis, clinical picture, diagnosis and treatment. Acta Neurochir (Wien). 1991;110(3-4):160-165.

3. Hodge CJ, Binet EF, Kieffer SA. Intradural herniation of lumbar intervertebral discs. Spine (Phila Pa 1976). 1978;3(4):346-350.

4. D'Andrea G, Trillò G, Roperto R, Celli P, Orlando ER, Ferrante L. Intradural lumbar disc herniations: the role of MRI in preoperative diagnosis and review of the literature. Neurosurg Rev. 2004;27(2):75-82.

5. Kataoka O, Nishibayashi Y, Sho T. Intradural lumbar disc herniation. Report of three cases with a review of the literature. Spine (Phila Pa 1976). 1989;14(5):529-533.

6. Kobayashi K, Imagama S, Matsubara Y, et al. Intradural disc herniation: radiographic findings and surgical results with a literature review. Clin Neurol Neurosurg. 2014;125:47-51.

7. Gunasekaran A, de los Reyes NKM, Walters J, Kazemi N. Clinical presentation, diagnosis, and surgical treatment of spontaneous cervical intradural disc herniations: a review of the literature. World Neurosurg. 2018;109:275-284.

8. Nam $\mathrm{KH}$, Han IH, Cho WH, Choi BK. A pure fluid-filled intradural cyst associated with intradural disc herniation and possible pathogenesis: a case report. Spine J. 2013;13(11):e11-e15.

9. Guan $Q$, Xing F, Long Y, Xiang Z. Cervical intradural disc herniation: a systematic review. J Clin Neurosci. 2018;48:1-6.

10. Lee H-W, Kwon Y-M. Traumatic intradural lumbar disc herniation without bone injury. Korean J Spine. 2013;10(3):181-184.

11. Lee JS, Suh KT. Intradural disc herniation at L5-S1 mimicking an intradural extramedullary spinal tumor: a case report. J Korean Med Sci. 2006;21(4):778-780.

12. Floeth F, Herdmann J. Chronic dura erosion and intradural lumbar disc herniation: CT and MR imaging and intraoperative photographs of a transdural sequestrectomy. Eur Spine J. 2012;21(suppl 4): S453-S457.

13. Pan J, Wang $Y$, Huang Y. Coexistence of intervertebral disc herniation with intradural schwannoma in a lumbar segment: a case report. World J Surg Oncol. 2016;14:113.

14. Kim H-S, Eun J-P, Park J-S. Intradural migration of a sequestrated lumbar disc fragment masquerading as a spinal intradural tumor. J Korean Neurosurg Soc. 2012;52(2):156-158.

15. Ducati LG, Silva MV, Brandão MM, Romero FR, Zanini MA. Intradural lumbar disc herniation: report of five cases with literature review. Eur Spine J. 2013;22(suppl 3):S404-S408.

16. Choi JY, Lee WS, Sung KH. Intradural lumbar disc herniation: is it predictable preoperatively? A report of two cases. Spine J. 2007;7(1):111-117. 
17. Wasserstrom R, Mamourian AC, Black JF, Lehman RA. Intradural lumbar disk fragment with ring enhancement on MR. AJNR Am J Neuroradiol. 1993;14(2):401-404.

18. Sasaji T, Horaguchi K, Yamada N, Iwai K. The specific sagittal magnetic resonance imaging of intradural extra-arachnoid lumbar disc herniation. Case Rep Med. 2012;2012:1-3.

19. Crivelli L, Dunet V. Intradural lumbar disc herniation detected by $3 D$ CISS MRI. BMJ Case Rep. 2017;2017:bcr2017221728.

20. Matsumoto T, Toyoda H, Terai H, Dohzono S, Hori Y, Nakamura $H$. Utility of discography as a preoperative diagnostic tool for intradural lumbar disc herniation. Asian Spine J. 2016;10(4):771-775.

21. Hidalgo-Ovejero AM, García-Mata S, Gozzi-Vallejo S, Izco-Cabezón T, Martínez-Morentín J, Martínez-Grande M. Intradural disc herniation and epidural gas: something more than a casual association? Spine (Phila Pa 1976). 2004;29(20):E463-E467.

22. Park Y-S, Hyun S-J, Kim K-J, Jahn T-A. Multiple intradural disc herniations masquerading as intradural extramedullary tumors: a case report and review of the literature. Korean J Spine. 2016;13(1): 30-32.

23. Tempel Z, Zhu X, McDowell MM, Agarwal N, Monaco EA III. Severe intradural lumbar disc herniation with cranially oriented free fragment migration. World Neurosurg. 2016;92:582.e1-582.e4.

24. Mut M, Berker M, Palaoĝlu S. Intraradicular disc herniations in the lumbar spine and a new classification of intradural disc herniations. Spinal Cord. 2001;39(10):545-548.

25. Tamaki $Y$, Sakai T, Miyagi R, et al. Intradural lumbar disc herniation after percutaneous endoscopic lumbar discectomy: case report. $J$ Neurosurg Spine. 2015;23(3):336-339.

\section{Disclosures}

Dr. Protopsaltis is a consultant for Globus, NuVasive, Stryker K2M, and Medtronic, earns royalties from Altus, and has stock options with Spine Align.

\section{Author Contributions}

Conception and design: Ihejirika, Protopsaltis. Acquisition of data: Ihejirika. Analysis and interpretation of data: Ihejirika, Protopsaltis. Drafting the article: all authors. Critically revising the article: Ihejirika, Tong, Protopsaltis. Reviewed submitted version of manuscript: Ihejirika, Tong, Protopsaltis. Approved the final version of the manuscript on behalf of all authors: Ihejirika. Statistical analysis: Ihejirika. Administrative/technical/material support: Ihejirika, Protopsaltis. Study supervision: Ihejirika, Protopsaltis.

\section{Supplemental Information \\ Video}

Video 1. https://vimeo.com/612691119.

\section{Correspondence}

Rivka Ihejirika: NYU Langone Orthopedic Hospital, New York, NY. rivka. inejirika@nyumc.org. 